\title{
Reducing the geometrical machining errors incurred during die repair and maintenance through electric discharge machining (EDM)
}

\author{
Kashif Ishfaq ${ }^{1} \cdot$ Muhammad Umar Farooq ${ }^{2}$ (I) $\cdot$ Catalin I. Pruncu $^{3}$ (D) \\ Received: 27 April 2021 / Accepted: 4 August 2021 / Published online: 26 August 2021 \\ (C) Crown 2021
}

\begin{abstract}
The importance of geometrical accuracy can never be overruled in dies and molds which governs the dimensional precision of the parts being manufactured. The continuous use of such tooling requires repair and maintenance. Among the different processes used to upkeep the dimensional consistency of the tooling, machining is essentially required in most cases. The intricacy of the dies and molds' cavities requires the use of electric discharge machining (EDM). However, in EDM it is challenging to develop control over the machined dimensions owing to the inherent issues of overcut/undercut. This aspect was not comprehensively investigated so far which is the core focus of this research. Three electrode materials, namely, copper, graphite, and tungsten carbide, which belong to the category of metals, nonmetals, and ceramics, respectively, have been compared for the said perspective on the comprehensive list of parametric variables. The results revealed that the average value of the axial errors is 2.5 times lesser in comparison to lateral dimensional errors. In the case of lateral dimensional errors, the electrode of graphite has proved to be a promising choice in comparison to the other two types of electrode materials, namely, copper and tungsten carbide. The copper electrode is noticed to be the most appealing option for reducing axial error (A.E). The mean A.E obtained with $\mathrm{Cu}$ electrode is $80.9 \%$ and $47.6 \%$ lower than that achieved in case graphite and tungsten carbide, respectively. Furthermore, the optimal parametric combination based on 7 variables has also been proposed using desirability analyses whose validity is proved during confirmation trials.
\end{abstract}

Keywords EDM · Copper · Graphite · Tungsten carbide · Accuracy errors · Lateral dimensional errors · Axial Errors · Repair and maintenance

\section{Introduction}

Industrialization has exponentially grown which has boosted the total factor productivity growth more in the manufacturing sector as compared to nonmanufacturing. Small and medium

Kashif Ishfaq

kashif.ishfaq@uet.edu.pk

Muhammad Umar Farooq

umarmuf0@gmail.com

Catalin I. Pruncu

Catalin.pruncu@strath.ac.uk

1 Department of Industrial and Manufacturing Engineering, University of Engineering and Technology, Lahore 54890, Pakistan

2 School of Mechanical Engineering, University of Leeds, Leeds LS2 9JT, UK

3 Design, Manufacturing \& Engineering Management, University of Strathclyde, Glasgow G1 1XJ, Scotland, UK enterprises around the world contribute to global manufacturing in high ratios [1]. In this regard, manufacturing is considered as one of the primary sources of wealth on which any country sustains its economy [2]. The tooling industry specialized in dies and molds has quite a remarkable share in global manufacturing. US-based toolmakers shifted the burden related to die and mold manufacturing to developing nations such as China. The shift provided an economical alternate which was unavailable before due to increased proximity to lowwage labor, price competitive environment, and shift of automobile industries. Large-scale production, varying designs, product customization, and trial experimentation because of evolving challenges require manufacturers to develop die and mold manufacturing capabilities in-house or staying close to parent industries as a second option [3].

The proximity to manufacturers is because of the high dependence of processes on dies and mold. In the automotive sector, there is the high use of such parts to process sheets, forge shapes, and manufacture molded parts. These critical 
components face various technical difficulties because of the high usage of dies [4]. The induced defects are shown in Fig 1. The manufacturing of these mechanical tools requires high investment and possesses significant production costs. Therefore, the repair and maintenance activities are preferred to reuse the defective tools to lower capital investment. The potential defects which require repairing action are dents, plastic deformation, wear, and crack [6, 7]. The plastic deformation is caused due to excessive use and fatigue loading on the die face. The fatigue loading initiates the crack and starts its promotion resulting in digging, edge deterioration, and overall failure. The possible processes which are employed for repair activity are shown in Fig 2 . The repair is carried out in two ways, firstly general clean-up and/or retouching and secondly hardcore processing. Some processes add material on the surface and then fill the cracks, dents, and other possible defects, while others process it to produce a whole new surface. The gas tungsten arc welding, laser deposition, thermal spraying, and electron beam welding usually add material and then shape it up as per desired geometry. However, high-speed machining, burnishing, and electric discharge machining usually processes worn surface to fabricate a new one as required. Burnishing adds surface quality to deal with the surface defects, while high-speed machining removes unwanted material to produce required features. Electric discharge machining removes unwanted material and modifies surface as well which enhances mechanical strength to save surface from possible defects. The die-making industry prefers highspeed machining since 1995, which questions the benefits of electric discharge machining having the constraint of the longer production times. However, the challenges to generate error-free programs, complex profiles, optimum cutting strategies, and tooling costs make other processes difficult to adopt. Therefore, the die-making industry usually compromises over production time against surface quality and intricacy [9-11]. Rodriguez et al. [8] used the deep ball burnishing process to improve surface characteristics. Similarly, intricate shapes are processed to improve the surface finish through ball burnishing; however, the micro-profiles and complex shapes which are an essential part of dies remained challenging to process $[12,13]$.

The importance of geometric accuracy can never be overruled in industrial applications considering the desired functionality of manufactured parts. In the manufacturing realm, there is much significance on dimensions verification in railway, aeronautical, defense, marine, and other sectors. Therefore, the accuracy of tools being used to fabricate many specialized parts is considered vital $[14,15]$. The tools are required for several mechanical works such as drawing, shaping, stamping, coining, blanking, forging, and general applications. Among various materials, steels used in these applications are categorized separately as tool steels. AISI D2 steel is very famous and the most utilized metal in the claims. The material contains a high proportion of carbon and chromium, often considered as hard material which is the basic requirement to serve under a heavy-duty environment. The preference of this material over other tool steels is due to its excellent compressive strength, good wear resistance, and strong stability [16]. All these engineering properties make the processing of the material difficult and uneconomical through

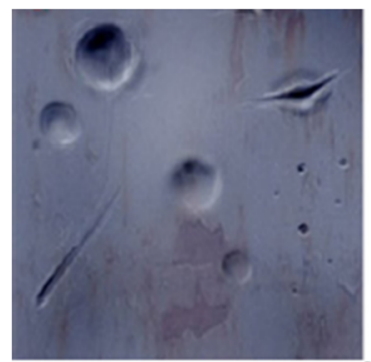

DENTS \& DIGGING
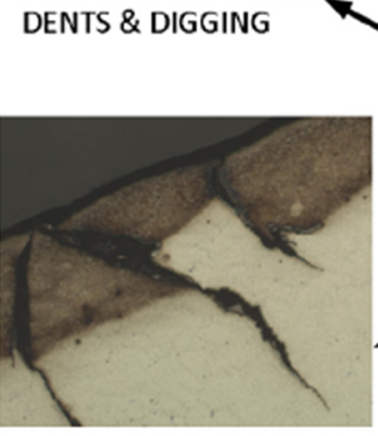

CRACK

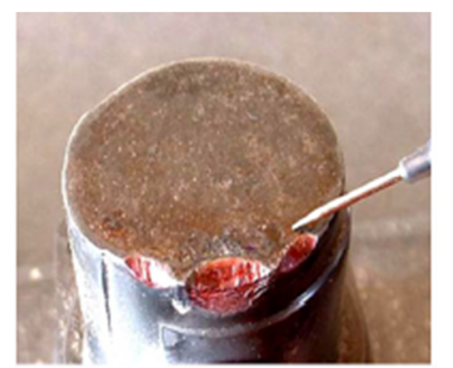

PLASTIC DEFORMATION

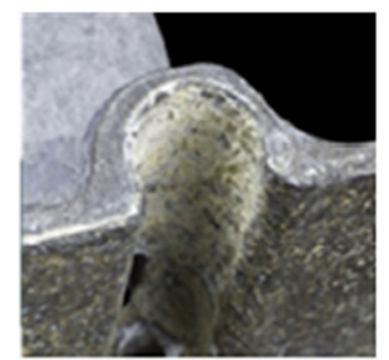

EDGE DETERIORATION

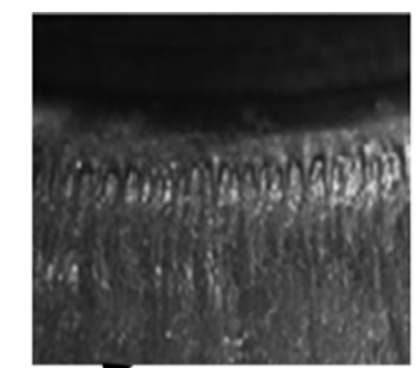

WEAR
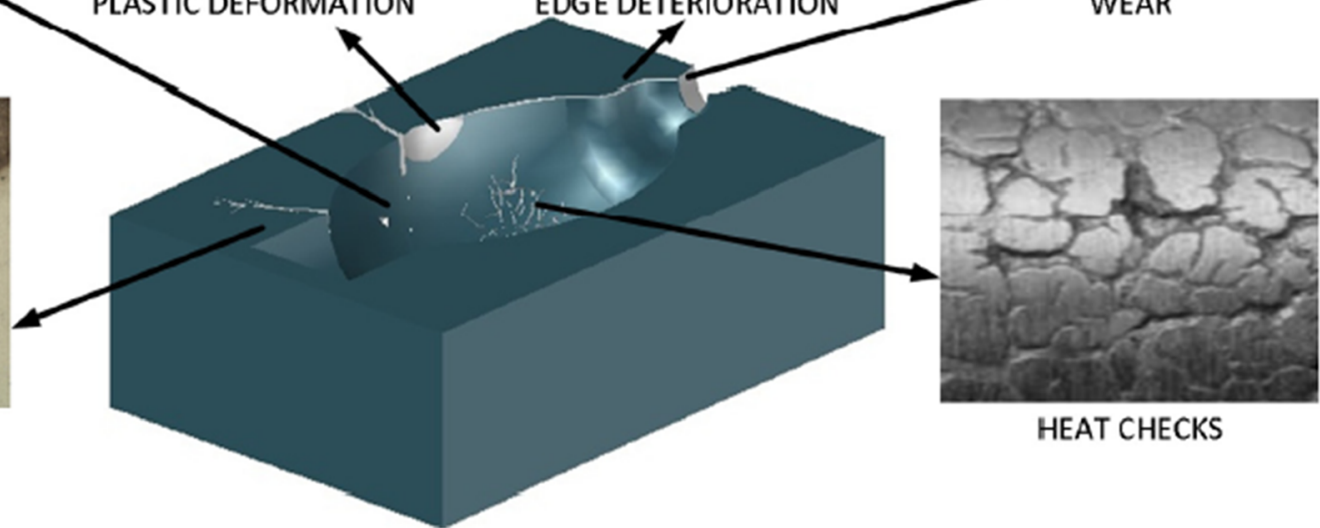

HEAT CHECKS

Fig. 1 Potential defects in die and mold [5] (copyrighted and reprint permissions taken) 
Fig. 2 Possible die repair and maintenance methods $[4,5,8]$ (copyrighted, redrawn and modified with permission)

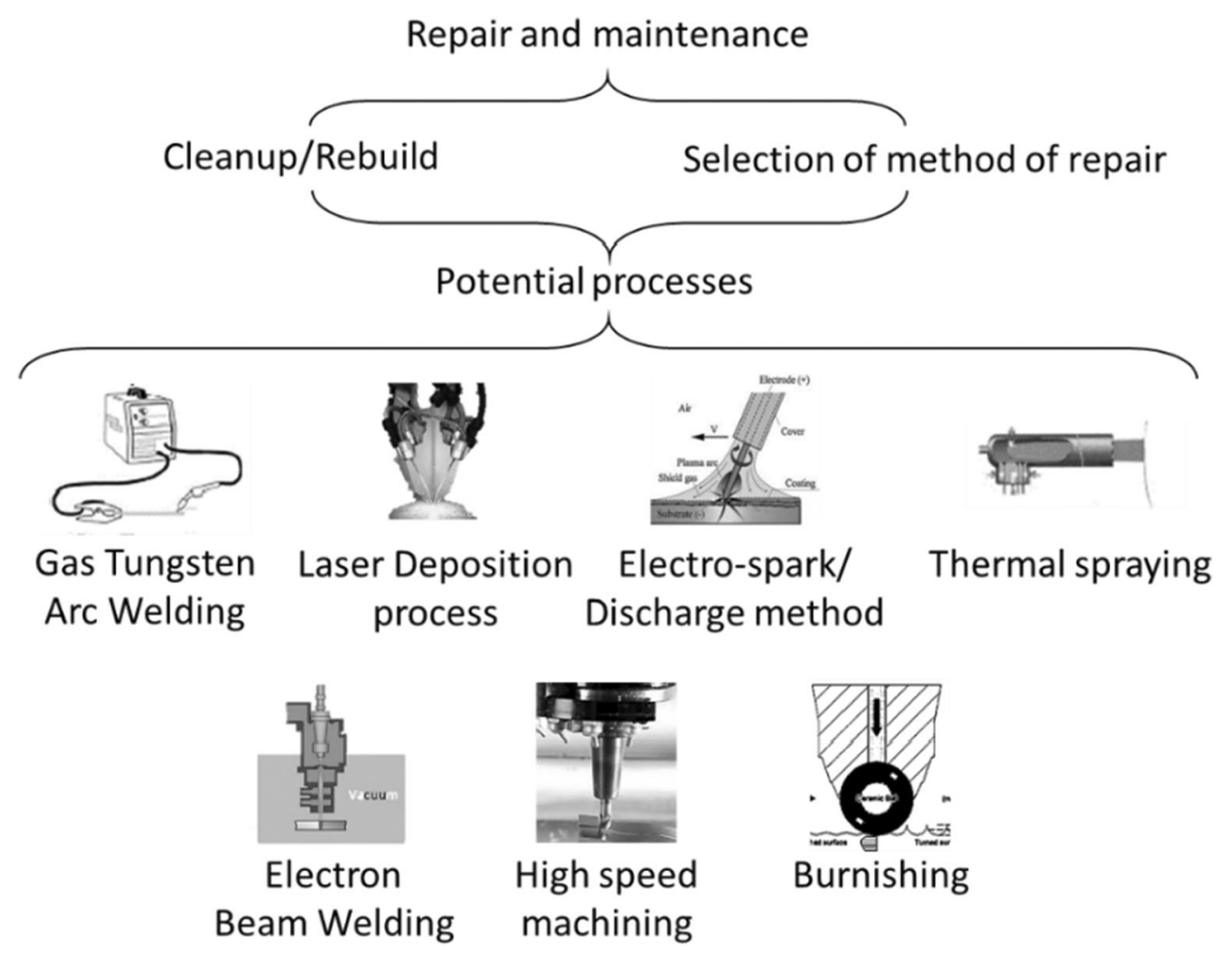

conventional means (milling, drilling, turning et al.). In addition to this, the accuracy obtained of the machined part is unacceptable in many cases while dealing with complex profiles for ultraprecision applications. Therefore, the requirement of precise complex parts ruled out the option to use conventional machining [17]. In the modern era, different nontraditional machining processes are developed to minimize material processing constraints [18]. Moreover, application-specific processes are employed to obtain the desired features with reasonable quality [19]. To machine dies and tools for mechanical works, electric discharge machining is the most preferred candidate because it does not depend on mechanical characteristics such as hardness, toughness, etc. of the workpiece due to no physical interaction between the tool and the workpiece [20]. In this process, the primary function is to evaporate and melt the material under the series of electric sparks controlled by discharge frequency.

The heat generated through these electric sparks dissipates in the tool and workpiece, representing the mechanism of the process as electrothermal [21]. The occurrence of this phenomenon results in the removal of material through melting, vaporization, and clearance of melted debris near those channels. Therefore, it can solely machine the desired shapes on the workpiece as compared to employing more than one process [22, 23], whereas electric discharge machining (EDM) can be employed not only for bulk material removal but also for surface texturing, surface hardening, layer quality improvement, material deposition, surface alloying, etc. The only constraint of EDM is the property of conductivity which is debatable as many researchers are trying to machine materials by inducing electrical conductivity. Any material showing reasonable thermal conductivity can be employed as the electrodes. However, materials having good electrical and thermal conductivity with higher melting temperatures can be a reasonable option for the selection of tool electrode material [22]. In addition to this, the tool electrode must qualify for providing geometric accuracy because of the good strength to reduce the edge errors. There are tool materials that erode very quickly but remove material effectively, while some erode the material in low magnitude against small electrode wear [24]. Therefore, the right selection of tool electrodes is a vital decision while employing the process to obtain the desired product quality [25]. In addition to these individualities, EDM holds the prominence in complex profiling under highdimensional dominance [26].

Focusing on the sovereignty of EDM in machining the complex shapes, it can be employed to machine AISI D2 steel for applications as tooling in aeronautical, defense, and automotive sectors. The intended use of the AISI D2 steel justifies the engagement of EDM as a machining process. With all these advantages of EDM, some limitations are also related $[27,28]$. Concerning dimensional accuracy of machined parts, dimensional shift, overcut, undercut, etc. are certain challenges. However, several researchers have been studying problems concerning accuracy in the past [14]. For instance, copper, brass, aluminum, and graphite were employed to 
evaluate the potentiality of EDM in fabricating microimpressions on different materials. The influence of parameters, namely polarity, pulse current, and pulse on- and off-time ratio, were evaluated against axial and lateral errors produced with each electrode material [29]. The inferences were that parametric control for an individual response was found easy as compared to simultaneous responses such as axial error, lateral error, material removal rate, and surface roughness. Jadidi et al. [17] varied external magnetic field while machining on AISI D2 steel to evaluate material removal rate and dimensional accuracy using the square copper tool. The effects of magnetic flux, pulse current, pulse on time, and workpiece revolutions were explored and optimized through grey relational analysis (GRA) for both responses. The magnetic environment increased the ion activity by increasing $42 \%$ material removal as compared to the traditional material removal approach. However, the workpiece revolution put a negative impact on dimensional accuracy by increasing overcut.

Sahu et al. [30] explored dielectric characteristics on surface crack density, recast layer thickness, crack depth, and tool wear rate (TWR) which causes taper angle along the walls of the hole. In the study, graphite and alumina powders were mixed in the dielectric and pulse current, on time, and duty cycle's effects were statistically gauged using analysis of variation. To reduce the surface irregularities and dimensional errors, graphite powder was recommended as compared to conventional dielectric and alumina. TWR was boosted with the increase in pulse current, and Sahu et al. considered TWR as a phenomenon directly contributing to dimensional errors. Therefore, in the study, low-pulse current values were suggested to reduce TWR which directly improves dimensional accuracy. In another study, Mufti et al. [31] introduced a relief angled tool design to improve the dimensional accuracy. In the analysis, multiple taper tools with and without land heights were used to minimize the overcut and undercut produced at the start and end of through-hole, hole taper angle, and the longitudinal TWR. The copper tool was employed due to its better conductivity to machine tungsten carbide. There are multiple types of dimensional errors such as hole taper error, axial error, radial error, overcut, undercut, etc. Among all, axial error and lateral errors are incidentally not explicitly focused on by researchers in the context of fabricating mechanical tools.

Ahmad et al. [32] studied dimetric overcut and material removal rate of EDM of Inconel 718 using the copper tool. Controlling peak current majorly controls material removal and overcut as well. Azhiri et al. [33] used ultrasonic vibrations to improve performance. The ultrasonic power was controlling the performance characteristics such as material removal, surface integrity, and residual stresses, by $20 \%, 15 \%$, and $15 \%$, respectively. The discharges associated with the setup act like a peening effect on the surface and improves the surface characteristics and also mobilizes the ionic activity. Optimization carried through GRA improved the results. Similarly, Dewangan et al. [34] utilized fuzzy TOPSIS and sensitivity analysis for the optimization of surface integrity and dimensional accuracy in terms of overcutting. Higher pulse current and on time have shown detrimental effects on both responses. Nguyen et al. [35] tried the integration of the electrochemical process with electric discharge machining to gain more control over dimensional accuracy. Partially deionized water was used as a dielectric in EDM to promote chemical decomposition by assimilating tool electrode speed. The hybrid process could make micro-impressions through focused material removal from both phenomena.

It is appropriate to point out that in several practical situations; for example, in the case of dies and molds, the machining is undertaken in both the cutting orientations such as axial and lateral direction to achieve required geometry on the desired profiles [36]. However, it is assumed that the magnitude of inaccuracies occurring in both directions would be of a similar quantification attribute. Though, in the real scenario, the level of inaccuracies that arose in the cutting directions is unique because of the changing spark intensity and the magnitude. Consequently, the present study serves as a thorough investigation on the effect of cutting direction along with the wide range of process variables to provide improved accuracy in both orientations against micro-impression for the goal of controlled machining. Moreover, during repair applications of dies, prime importance is given to product accuracy, because inaccurate dimensions can lead towards dimensional stack-up error in assembly. This primary concern for the shape accuracy in both cutting directions has not been unequivocally directed yet which is a prime attribute of the present research. From the scrutiny of literature, it can be extrapolated that the investigation of electric discharge machining parametric effect on material removal and surface roughness has remained the machinists and researchers' interest. Regarding the AISI D2 steel applications in the machine tooling industry, many times machinist requires to produce machining features with targeted depths or machined volumes such as the development of cavities or other features in molds and dies. In this aspect, control over material removal is necessary to get the precise geometry of the profile. Since there is no comprehensive work present in a similar aspect, therefore, a wide range of machine parameters is selected to thoroughly explore the parametric effect on the accuracy features. Thus, the factors affecting the control over the material removal in terms of axial and lateral dimensions producing dimensional errors have been sought, and an optimized range of machine settings is recommended using a multi-attribute optimization algorithm, which is the unique and novel aspect of the present work. Therefore, a huge effort of the machinist can be significantly reduced which otherwise need to spare for reaching the suitable parameters capable of producing the precise dimensions of the machined feature. 


\section{Materials and methods}

AISI D2 steel was used as a workpiece due to its high use in the mechanical work industry. The tools fabricated by the afore-cited material are commercially used in the aeronautical, defense, and automotive sectors. The composition was confirmed by optical emission spectroscopy as per the sheet provided by the manufacturer. The detailed composition is provided in Table 1. As material usability is required in highly precise applications, therefore, it is subjected to EDM die sinking due to its popularity in die-making industries. The literature is present on the processing of AISI D2 steel in the context of material removal, surface hardening through layer deposition, surface roughness, and other features. However, less attention is made towards the precision and accuracy explicitly on the axial and lateral errors, though some researchers made initial investigations in the perspective of overcutting.

Therefore, the accuracy issues are investigated herein. Since not many studies are present in a similar context, that is why a wide range of seven control variables are selected to thoroughly study the problem. Seven input control variables, namely spark time $\left(\mathrm{S}_{\mathrm{T}}\right)$, tool material $\left(\mathrm{T}_{\mathrm{M}}\right)$, pulse-on time $\left(\mathrm{P}_{\mathrm{ON}}\right)$, pulse-off time $\left(\mathrm{P}_{\mathrm{OFF}}\right)$, flushing time $\left(\mathrm{F}_{\mathrm{T}}\right)$, peak current $\left(I_{P}\right)$, and spark voltage $\left(V_{S}\right)$. The reason behind the selection of these variables is due to their significant role proved on other machining aspects as evident in literature [22, 25, 31]. The physical properties of all tool electrodes and workpiece which play a significant role during electric discharge machining are mentioned in Table $2[37,38]$. The tool electrodes used for experimentation are copper, graphite, and tungsten carbide. Tungsten carbide (WC-Co) is a refractory metal having a melting point of around $2900{ }^{\circ} \mathrm{C}$ and is made by powder metallurgy technique, wherein tungsten carbide and cobalt as binder metal powder are pressed and sintered.

The differences between the original dimension and the achieved dimension in axial (depth) and lateral orientation are categorized as lateral errors (L.E $\left.E_{X}, L . E_{Y}\right)$ and axial error (A.E). These dimensions play a pivotal role in establishing the accuracy of machined sample and, therefore, are considered herein.

The appropriate selection of input control parameters and their ranges largely affect the response indicators [39]. However, due to the unavailability of ranges in similar perspectives, the level selection is carried out through preliminary experimentation, because these levels are determinants of product quality in machining. Different problems during preliminary experimentation were considered such as mild burns on the surface, unstable sparking, etc. Only those parametric settings are employed on which these problems have been at a minimum. There are seven input control variables having 3 levels against 6 variables and two against one, which requires extensive experimentation under the full factorial design of experiments. The features explored in current research are novel; therefore, a wide range of control variables is taken into account. The focus of the use of parameters in the literature shows the efficacy of variables to support the rationale behind the selection. In addition, the physical science of the variables affecting dimensional accuracy is thoroughly discussed in Section 3.1. Parametric effects on dimensional accuracy. Whereas considering the cost and time constraint, Taguchi design of experimentation methodology has opted, and $\mathrm{L}_{18}$ is found suitable for the mature experimentation. In statistics dealing with product quality, Taguchi robust design of experiments is given vital importance due to its unique features. It cuts short the number of experiments and provides robust analysis based on signal to noise ratio. In addition, the methodology is widely used in material processing research [14] because of experimentation time and cost constraints. The parametric details are provided in Table 3 . The tool electrodes having square geometry of $10 \times 10 \mathrm{~mm}^{2}$ were used with the designed depth of cut of $0.5 \mathrm{~mm}$. In total 18 experiments have been conducted on EDM die sinker (model: Rj230 manufactured by Creator, Taiwan) in a randomized manner. Electric discharge machining is a controlled nonconventional process using pulsed electric discharges to erode unwanted material. The pulsed power generators apply voltage pulses to remove the metal through melting and vaporization. It uses relaxation technology-based capacity generators to control the thermal energy transfer. Before each experimental run, the external conditions such as resistivity of dielectric and clamping pressure were maintained, and the workpiece was clamped orthogonally for the accurate measurement of lateral error. During each run, in the (x-axis) lateral direction, lengths in both orientations were measured in $\mathrm{x}\left(\mathrm{L} . \mathrm{E}_{\mathrm{X}}\right)$ and $\mathrm{y}\left(\mathrm{L} . \mathrm{E}_{\mathrm{Y}}\right)$ sub-directions. The error produced in achieving the designed depth is stated as an axial error (A.E). For the measurement of L.E $E_{X}, L . E_{Y}$, and A.E, a coordinate measure machine is used by taking five consecutive points and taking the average of the distances. The schematic illustration and cavities produced during experiments are shown in Fig. 3. A dedicated statistical parametric influence analysis is carried out followed by the microscopic analysis to explore the physical phenomenon.
Table 1 Composition of AISI D2 steel

\begin{tabular}{llllllllllll}
\hline Element & $\mathrm{C}$ & $\mathrm{Mn}$ & $\mathrm{Si}$ & $\mathrm{Co}$ & $\mathrm{Cr}$ & $\mathrm{Mo}$ & $\mathrm{V}$ & $\mathrm{P}$ & $\mathrm{Ni}$ & $\mathrm{Cu}$ & $\mathrm{S}$ \\
\hline Weight \% & $1.4-1.6$ & 0.6 & 0.6 & 1 & $11-13$ & $0.7-1.2$ & 1.1 & 0.03 & 0.30 & 0.25 & 0.03 \\
\hline
\end{tabular}


Table 2 Potential thermophysical attributes of tool and workpiece materials to affect the EDM process

\begin{tabular}{llllll}
\hline Properties & \multicolumn{2}{l}{ Tool } & & \multicolumn{2}{l}{ Workpiece properties } \\
\cline { 2 - 4 } & Copper & Graphite & Tungsten carbide & \\
\hline Density $\left(\mathrm{g} / \mathrm{cm}^{3}\right)$ & 8.905 & 1.77 & 15.25 & Density $\left(\mathrm{g} / \mathrm{cm}^{3}\right)$ & 7.7 \\
Melting Point $\left({ }^{\circ} \mathrm{C}\right)$ & 1083 & 3300 & 2727 & Melting point $\left({ }^{\circ} \mathrm{C}\right)$ & 1421 \\
Thermal Conductivity & 385 & 400 & 88 & Thermal conductivity & 21 \\
$(\mathrm{~W} / \mathrm{m} \mathrm{K})$ & & & & (W/m K) & \\
Electrical Conductivity & $59.6 \times 10^{6}$ & $0.30 \times 10^{6}$ & $2.39 \times 10^{6}$ & & \\
$(\mathrm{~S} / \mathrm{m})$ & & & & & \\
\hline
\end{tabular}

\section{Results and discussions}

\subsection{Parametric effects on dimensional accuracy}

The experimental outcomes are meticulously analyzed after effective accomplishment of experimentation based on $\mathrm{L}_{18}$ orthogonal array in a randomized manner under constant conditions such as resistivity of dielectric, stability of the tool, and workpiece through gravity fall method. To investigate the parametric effects, the main effect plots help to visualize and compare the trend of responses against each level of input variable. Figures 4-6 present the analysis of means (AOM) of responses. The statistical analysis takes out the average at each level of parameter from the set of experiments and plots it on the graph. The AOM shows the average values obtained through the experimentation, yet we have noted using a specific level of variable can limit the description of interactions between parameters. These parametric effects plots are shown in Fig. 4, Fig. 5, and Fig. 6 for L.E $E_{X}$, L.E $E_{Y}$, and A.E, respectively. Owing to the significance of each parameter on geometrical errors, their effects are discussed supporting through physical phenomenon involved. Moreover, their influence is backed by the essence of literature.
It can be observed from the main effect's plot of L. $E_{X}$ provided in Fig. 4 that spark time $\left(\mathrm{S}_{\mathrm{T}}\right)$ has an inverse relation with the error. With the increase in spark time, the discharge strength sprawls in a lateral direction resulting in an overcut. Overall, the increase is of few microns in overcutting against 3 to $9 \mu \mathrm{s}$ shift in control variable, whereas graphite tool electrode gives the highest strength and sharp corners of impression with minimum lateral error in the $\mathrm{x}$-direction. The reason behind the significantly low error is the highest thermal conductivity $(400 \mathrm{~W} / \mathrm{m} \mathrm{K})$ among other tool materials $\left(\mathrm{T}_{\mathrm{M}}\right)$. Copper which also has comparable heat conduction $(385$ $\mathrm{W} / \mathrm{m} \mathrm{K}$ ) marks the second place in reducing the lateral error. The traces of mild marks and adequate material removal are shown in Fig. 7. The shallow surface of the tool (see Fig. 7(a)) is evident of energy transfer and material removal in the form of debris. It controls the unwanted surface removal adequately to produce a highly accurate profile. Moreover, the small craters of low depth ensure the flatness of the surface which is desired [40]. The surface is the result of controlled profile machining required to achieve set dimensions. A potentially smooth surface (see Fig. $7(b, c)$ ) is achieved in comparison to data presented in Fig. 8.

Contrarily, tungsten carbide is not a good conductor of heat ( $88 \mathrm{~W} / \mathrm{m} \mathrm{K}$ ) and gives the highest error. This is because the
Table 3 Details of input control variables, their levels and responses

\begin{tabular}{|c|c|c|c|c|c|c|c|}
\hline \multirow[t]{2}{*}{ Input Parameters } & \multicolumn{3}{|l|}{ Levels } & \multirow[t]{2}{*}{ Units } & \multicolumn{3}{|l|}{ Response variables } \\
\hline & 1 & 2 & 3 & & Response attribute & Symbol & Units \\
\hline Spark time $\left(\mathrm{S}_{\mathrm{T}}\right)$ & 3 & 9 & - & $\mu \mathrm{s}$ & Axial dimensional & A.E & $\mu \mathrm{m}$ \\
\hline $\begin{array}{l}\text { Tool material } \\
\qquad\left(\mathrm{T}_{\mathrm{M}}\right)\end{array}$ & Copper & Graphite & $\begin{array}{r}\text { Tungsten } \\
\text { carbide }\end{array}$ & - & error & & \\
\hline $\begin{array}{l}\text { Pulse-on time } \\
\left(\mathrm{P}_{\mathrm{ON}}\right)\end{array}$ & 70 & 110 & 150 & $\mu \mathrm{s}$ & $\begin{array}{l}\text { Lateral dimensional } \\
\text { error }\end{array}$ & L.E ${ }_{X}$ & $\mu \mathrm{m}$ \\
\hline $\begin{array}{l}\text { Pulse-off time } \\
\left(\mathrm{P}_{\mathrm{OFF}}\right)\end{array}$ & 30 & 60 & 90 & $\mu \mathrm{s}$ & & L.E $E_{Y}$ & $\mu \mathrm{m}$ \\
\hline $\begin{array}{l}\text { Flushing time } \\
\qquad\left(\mathrm{F}_{\mathrm{T}}\right)\end{array}$ & 3 & 6 & 9 & $\mu \mathrm{s}$ & & & \\
\hline Peak current $\left(\mathrm{I}_{\mathrm{P}}\right)$ & 8 & 12 & 16 & A & & & \\
\hline $\begin{array}{l}\text { Spark voltage } \\
\left(\mathrm{V}_{\mathrm{S}}\right)\end{array}$ & 3 & 5 & 7 & $\mathrm{~V}$ & & & \\
\hline
\end{tabular}




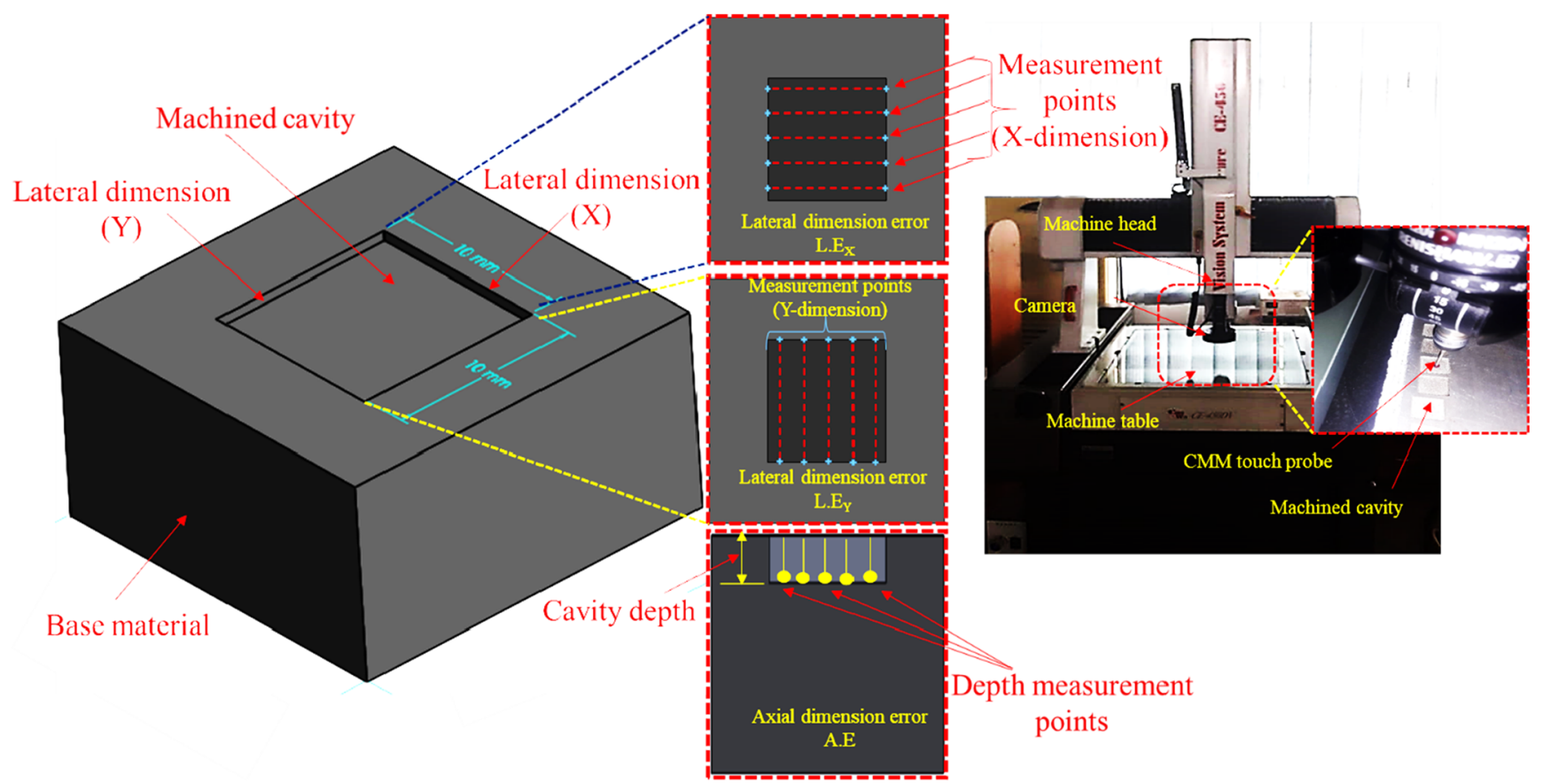

Fig. 3 Illustration of machined cavity, measurement procedure, measurement setup

heat flux generated on the interaction area does not find a chance to dissipate. The spark energy generates the melt pool, and the subsequent energy remains in the pool enlarging its volume leading towards high error in the lateral direction.

Figure 8(a) shows the connected craters which warrant a high number of discharges. However, the connected craters do not make deep irregularities on the tool surface because of low-heat conduction and energy dissipation by the work material. On the other end, the machined surface of the workpiece is crowded with craters. The surface generated shows the irregular activity of process energy as presented in Fig. 8(b, c). Moreover, craters' depth affirms a larger heat energy input to the tool-workpiece interaction. These are also intensified with varying current conditions. The discharges which are discretely penetrative to material convert the work material to liquid. The liquid puddle thus formed is subjected to flushing through

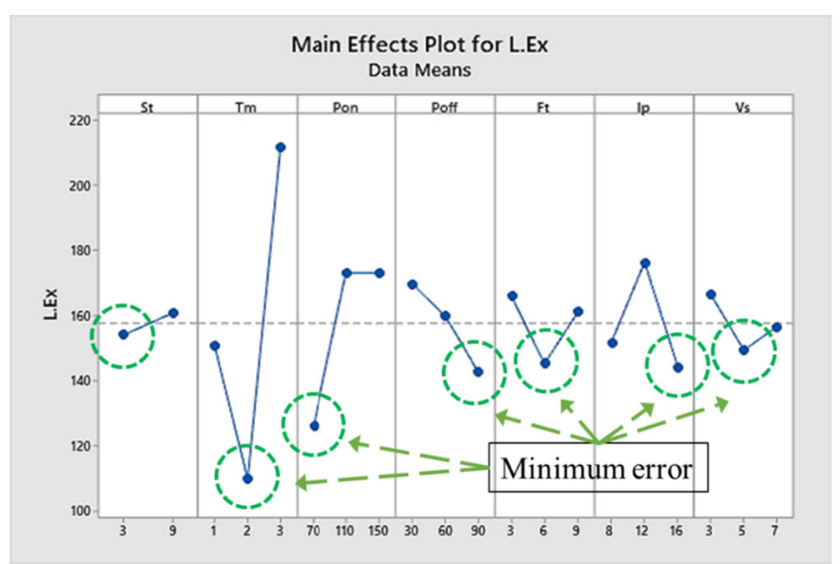

Fig. 4 Parametric effects for L. $E_{X}$ flowing dielectric to remove the debris. This action removes the unwanted material and ensures the ejection of debris from the material surface, making more deeper and wider craters on the machined region. The evidence of craters on the machined cavity is available in Fig. 8 which establishes the process science because of the thermal and electrical properties of tungsten carbide material (see Table 2). The low thermal conductivity of the workpiece also contributes to the high magnitude of L. $E_{X}$ because it warrants high material removal due to the inadequacy of heat dissipation in the workpiece to reduce the impact of discharges. This leads to an increase in the width and depth of the craters. In addition, the tungsten carbide tool is potentially employed as a forming tool, which is a basic feature of EDM to fabricate the negative profile of the tool on the workpiece. This adds more value to die-making industries.

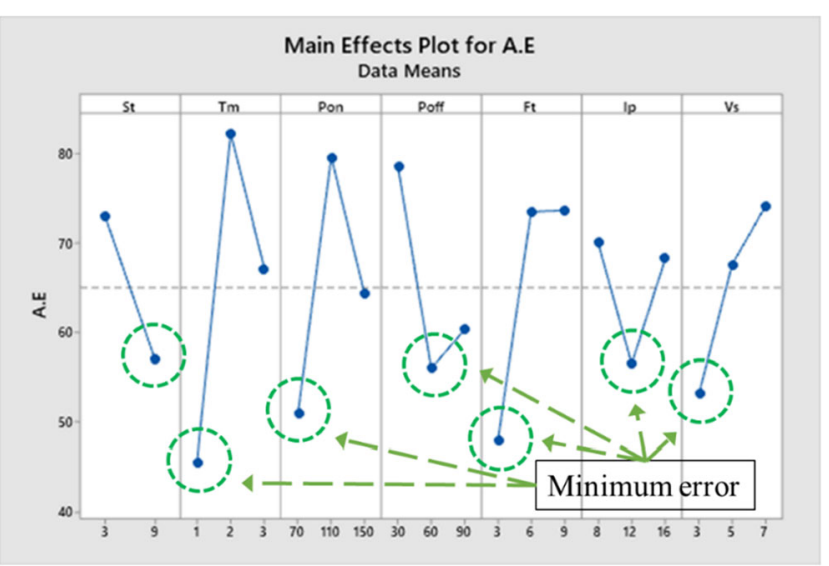

Fig. 6 Parametric effects for A.E 


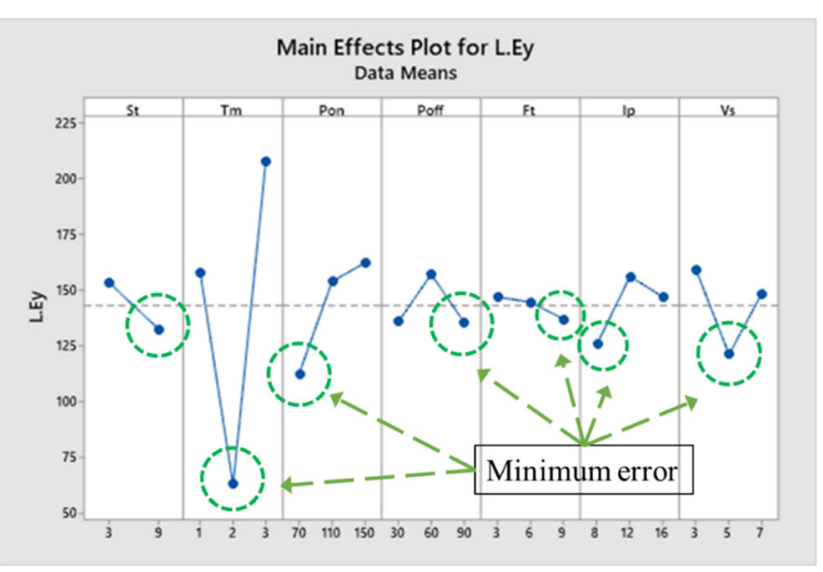

Fig. 5 Parametric effects for L. $E_{Y}$

The value of L. $E_{X}$ is also noted sensitive to the variation in the pulse on time $\left(\mathrm{P}_{\mathrm{ON}}\right)$ as highlighted in Fig. 4. The behavior of pulse on time $\left(\mathrm{P}_{\mathrm{ON}}\right)$ is increasing with respect to lateral error as high energy transfer takes place. At $70 \mu \mathrm{s}$ of $\mathrm{P}_{\mathrm{ON}}$ (the lowest level), a smaller heat flux stimulates in the toolworkpiece interaction area which eliminates a smaller volume of debris from the material surface. Therefore, a lesser error value is realized. This error value is also linked with the adequacy in unwanted material evacuation from the cavity during the pulse time [30]. The improper removal fosters the melted debris to redeposit on the newly generated surface. Accordingly, the extent of the L. $E_{X}$ is lowered. In contrast, the magnitude of L. $E_{X}$ is upsurge with the rise in $P_{O N}$ up to $110 \mu \mathrm{s}$. Approximately $60-\mu \mathrm{m}$ rise in L. $\mathrm{E}_{\mathrm{X}}$ is noticed as $\mathrm{P}_{\mathrm{ON}}$ is raised from 70 to $110 \mu \mathrm{s}$. This increase in L. $E_{X}$ is because of the increased content of heat energy applied for an extended time duration. The role of $\mathrm{P}_{\mathrm{ON}}$ in EDM is to regulate the discharge time length, and if the higher magnitude is applied, it implies sparking is offered for an extended time. The prolonged spark duration created more discharge energy that generates craters significantly deep and wide. Thus, the breadth of the impression is broadened. Further increase in $\mathrm{P}_{\mathrm{ON}}$ does not increase error and the curves remain steady.

For the case of $\mathrm{P}_{\mathrm{OFF}}$, there is an inverse relation of $\mathrm{L} . \mathrm{E}_{\mathrm{X}}$ with the flushing off-time as illustrated in Fig. 4. A rise in $\mathrm{P}_{\mathrm{OFF}}$ from 30 to $90 \mu$ s produces lesser overcut. The use of $30 \mu \mathrm{s}$ results in approximately $170 \mu \mathrm{m}$. The magnitude of overcutting reduces as the amount of $\mathrm{P}_{\mathrm{OFF}}$ is raised from 60 to $90 \mu \mathrm{s}$. With the high value of $\mathrm{P}_{\mathrm{OFF}}$, superior flush-action happens, it is because no sparking occurs during the $\mathrm{P}_{\mathrm{OFF}}$ period. Therefore, the molten material is efficiently flushed away because of the extended pulse-off duration that helps in attaining a smaller overcut. The lateral dimensional error L. $E_{X}$ also gets affected if flushing time $\left(F_{T}\right)$ is changed as depicted in Fig. 4. With the increase in flushing time $\left(\mathrm{F}_{\mathrm{T}}\right)$ from 3 to $6 \mu \mathrm{s}$, the lateral dimensional error decreased to $\sim 20 \mu \mathrm{m}$. This leads to induce adequate discharge energy under the influence of adequate flushing action to remove debris and melt from the craters [26]. Accordingly, the error magnitude of the cut impression is decreased. On contrary, if $\mathrm{F}_{\mathrm{T}}$ increases beyond $6 \mu \mathrm{s}$, and the L. $E_{X}$ is amplified in place of being decreased. This happens due to ineffective flushing of the melted debris and resolidifies at the surface as a consequence of an unbalanced stream of flushing [15]. In fact, a larger value of $\mathrm{F}_{\mathrm{T}}$ enhances flushing activity which leads to instability of discharges. Therefore, inadequate material is removed which leads to significant error $\sim 160 \mu \mathrm{m}$ when imposing $6 \mu \mathrm{s}$.

There is an increase in pulse current $\left(\mathrm{I}_{\mathrm{P}}\right)$ from 8 to $12 \mathrm{~A}$ grades in additional discharge energy from the tool to workpiece. This further results in increasing the size of craters as well as the overcut whose value reaches $\sim 180 \mu \mathrm{m}$. However, with an additional increase of $\mathrm{I}_{\mathrm{P}}$ from 12 to $16 \mathrm{~A}$, the adequacy of energy transfer matches the requirement of material removal [29]. This leads to a sufficient melt pool which improves dimensional accuracy in the lateral direction. The L. $E_{X}$ also reduces if servo voltage $\left(\mathrm{V}_{\mathrm{S}}\right)$ is improved up to a certain threshold, i.e., $5 \mathrm{~V} . \mathrm{V}_{\mathrm{S}}$ basically controls the advances and retracts of the tool electrode while maintains the necessary discharge gap [16]. When the $\mathrm{V}_{\mathrm{S}}$ is enhanced to $5 \mathrm{~V}$, the spark gap is enlarged which reduces the amount of energy transfer to the target surface [41]. Material erosion takes place in a smooth manner as electric sparking cannot penetrate deeply in the work part to damage its dimensions. But beyond $5 \mathrm{~V}$, L. $E_{X}$ has increased once again. Essentially, in EDM, the increase in $\mathrm{V}_{\mathrm{S}}$ stemmed from a consequent degradation in the cutting efficiency aspect. This lower value of material removed, making the evacuation of melted droplets complex, and unflushed droplets are resolidified again at the processed surface [42].
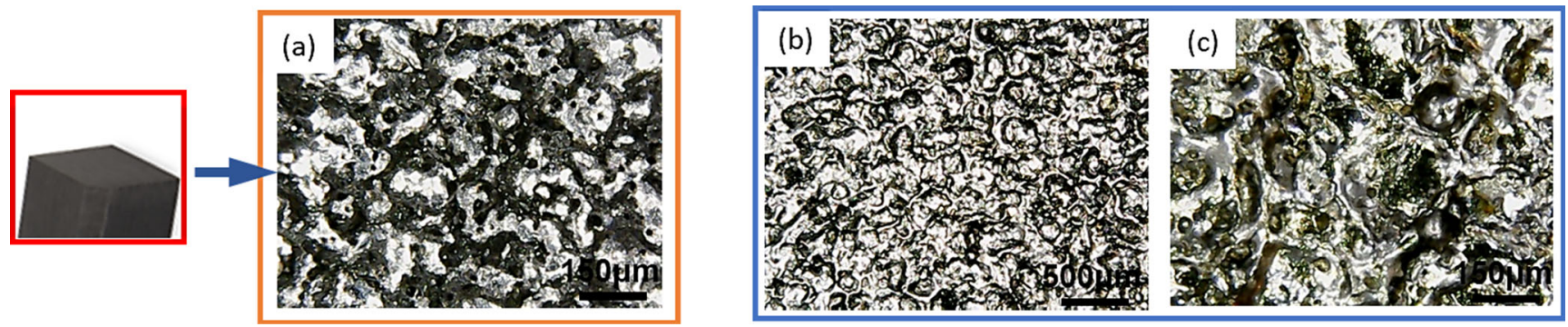

Fig. 7 Surface topography produced through discharge machining process: a graphite tool surface after machining, b workpiece surface machined against repair application, $\mathbf{c}$ magnified view of the surface 

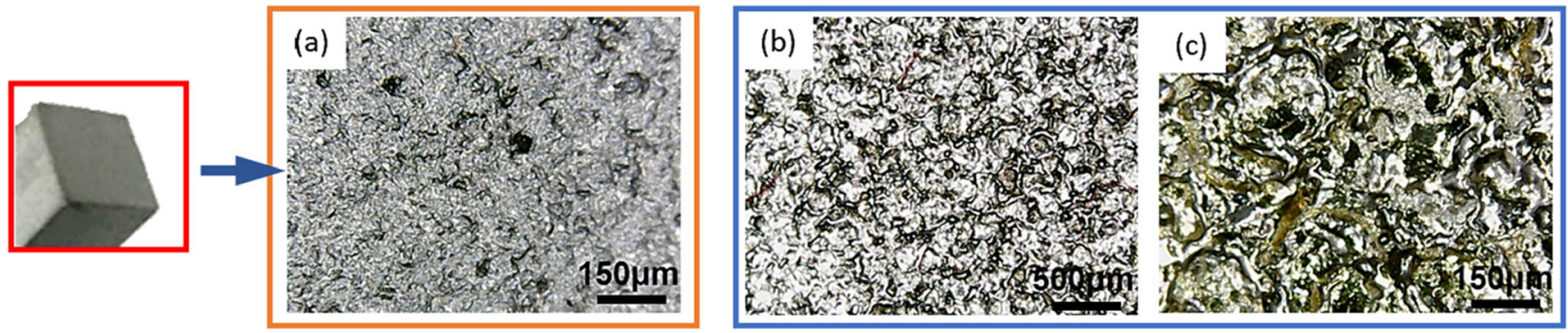

Fig. 8 Surface topography produced through discharge machining process: a tungsten carbide tool surface after machining, b workpiece surface machined against repair application, $\mathbf{c}$ magnified view of the surface

Similarly, L.E $E_{Y}$ follows similar parametric trends as the physical phenomenon involved is the same in the lateral direction as shown in Fig. 5. However, the magnitudes of errors noticed in both the cutting orientations, i.e., L.E $E_{X}$ and L.E $E_{Y}$, are noticeably different as depicted in Figs. 4 and 5. Likewise, in L.E $E_{X}$, graphite gives the lowest lateral error and edge strength in the case of L.E $E_{Y}$ as the phenomenon is discussed earlier, whereas $S_{T}$ behaves inversely in the case of L.E $E_{Y}$, i.e., high spark time leads to an accurate profile formation. $\mathrm{P}_{\mathrm{ON}}$ exactly followed the previously discussed trend, whereas the $\mathrm{P}_{\mathrm{OFF}}$ trend is slightly tailed as shown in Fig. 5. The additional increase in $\mathrm{P}_{\mathrm{OFF}}$ value (beyond $60 \mu \mathrm{s}$ ) helps to match the flushing action with the generated melt pool by added stability to the sparks which eventually results in the reduction of error. The removal of unwanted debris, melt pool, and undesired material is ensured by high values of flushing time $\mathrm{F}_{\mathrm{T}}$, whereas $I_{P}$ and $V_{S}$ followed similar behavior as shown in L. $E_{X}$ in Fig. 4.

The trend of parametric effects in the case of A.E is illustrated in Fig. 6. With the increase in spark time $\left(\mathrm{S}_{\mathrm{T}}\right)$ from 3 to $9 \mu \mathrm{s}$, a comparable decrease in axial error (A.E) can be observed. The designed depth achievement is improved, and A.E reduces from $\sim 72$ to $\sim 58 \mu \mathrm{m}$. The decrease in axial error is because of the increase in spark time which increases the melt volume as well as the energy transfer to the workpiece which leads to desired material removal ultimately reducing the error [31]. The behavior with respect to material removal is entirely reverse as observed in Fig. 4 and Fig. 5. Copper offers the highest material removal adequacy as compared to graphite and tungsten carbide. The material removal is highly dependent on thermal as well as electrical conductivity. Copper $\left(59.6 \times 10^{6} \mathrm{~S} / \mathrm{m}\right)$ has highest electrical conductivity as compared to graphite $\left(0.30 \times 10^{6} \mathrm{~S} / \mathrm{m}\right)$ and tungsten carbide $(2.39$ $\left.\times 10^{6} \mathrm{~S} / \mathrm{m}\right)[38]$.

Therefore, it helps to achieve desired depth through precise discharge series on the interaction area [22]. The highly electrically conductive post-machined electrode surface is displayed in Fig. 9(a). The lower level of pulse on time $\left(\mathrm{P}_{\mathrm{ON}}\right)$ of $70 \mu \mathrm{s}$ offers the smallest error of $\sim 50 \mu \mathrm{m}$. With the small increase in $\mathrm{P}_{\mathrm{ON}}$ to $110 \mu \mathrm{s}$, error drastically increased $(\sim 80 \mu \mathrm{m})$ due to unbalance between the energy transfer and flushing action. But beyond $110 \mu \mathrm{s}$, the error got reduced.
Actually, the greater value of pulse on duration ensures the existence of a melt pool for a longer period due to the availability of high discharge energy in the machining regime. This helps in efficient evacuation of the melted debris from the cavity which ultimately translated to better achievement of machined cavity's depth. Thus, A.E is reduced (error $\sim 65$ $\mu \mathrm{m})$. Pulse-off time $\left(\mathrm{P}_{\mathrm{OFF}}\right)$ partially follows the behavior of L.EX. The minimum axial error $\sim 57 \mu \mathrm{m}$ is obtained at $60 \mu \mathrm{s}$ of $\mathrm{P}_{\mathrm{OFF}}$. In addition to this, the right level of flushing is an incredibly important factor in achieving the desired depth. This leads to required debris removal or instability of spark generation promoting inadequate melting [23]. Therefore, the lowest level of $\mathrm{F}_{\mathrm{T}}(3 \mu \mathrm{s})$ offers the highest achievement of desired depth of cut showing the axial error of $\sim 47 \mu \mathrm{m}$. With the increase in $\mathrm{F}_{\mathrm{T}}$, axial error increased remarkably because of insufficient erosion action. $\mathrm{I}_{\mathrm{P}}$ followed reverse behavior as compared to L.E $E_{X}$ and L.E. $E_{Y}$. The middle value $(12 \mathrm{~A})$ realizes the dimensional accuracy $(\sim 56 \mu \mathrm{m})$ as it gives the right match of heat energy transfer which is increased on $8 \mathrm{~A}$ as well as 16 A. In the case of $V_{S}$ which controls the discharge gap directly and is considered responsible for the heat energy transfer, a greater value of $V_{S}$ provides higher A.E. With the increase in discharge gap, the sufficient removal of material is not insured causing an increase in dimensional error [22]. Therefore, a smaller level of $\mathrm{V}_{\mathrm{S}}$ fulfills the commitment of precise machining.

\subsection{Microstructure and surface texture analysis}

The effect of tool material on dimensional errors is quantified in Fig. 10. Considering copper and tungsten carbide tools results in considerably elevated linear dimensional errors (L.E $E_{X}$ and L.E $E_{Y}$ ) in comparison to graphite electrode irrespective of the level of current. The chart illustrates the superiority of copper tool-electrode in achieving the minimum axial dimensional error for attaining the micro-depth of the required shape. Nevertheless, the response of the copper electrode is completely opposite in the background of linear dimensional error. The average magnitude of linear dimension error (A.E) instigated by the graphite electrode is conspicuously lesser $(62.84 \mu \mathrm{m})$ in comparison to the error values correlated with the remaining two tools as emphasized. In general, it can be 

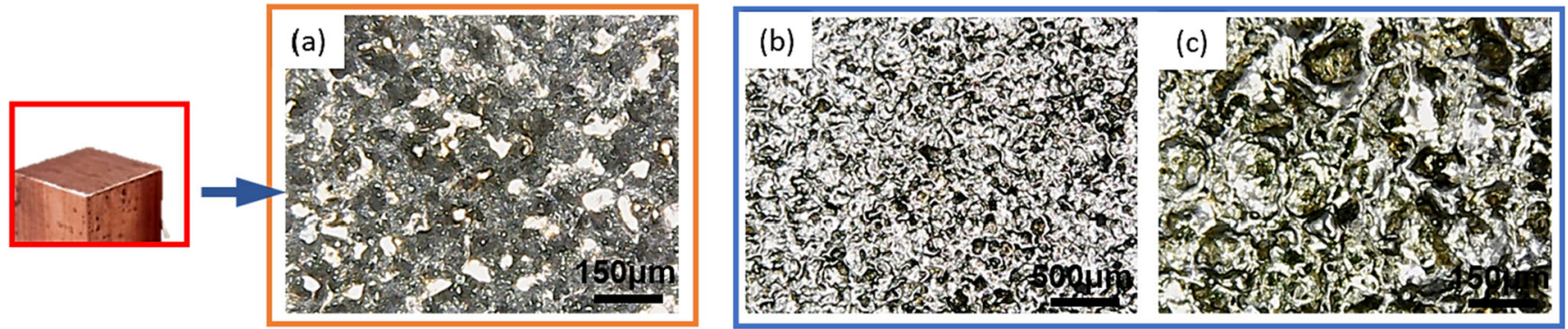

Fig. 9 Surface topography produced through discharge machining process: a copper tool surface after machining, b workpiece surface machined against repair application, $\mathbf{c}$ magnified view of the surface

stated that the graphite electrode decreases the linear dimension errors. Contrarily, the magnitude of axial dimension error reaches the highest level of $82.33 \mu \mathrm{m}$ with graphite electrode. On the other end, the copper tool can be a highly favorable choice in machining micro-sized shapes with sophisticated impressions yielding a low degree of axial errors. Though, the recorded error is nearly $45.5 \mu \mathrm{m}$. Therefore, evaluating all the details from Fig. 10 and Fig. 7-9, it can be implied that the graphite tool has the potential to be selected as the suitable preference in the case of linear dimension errors (L.Ex, L.Ey). Copper is the 2 nd preferred choice in this category.

According to the fundamental science of sparking-based erosive theory, the plasma pool is generated between the electrodes during sparking activity in EDM. The generation of spark-based plasma leads the material surface to be melted generating the craters and ridges [43]. The volume of produced craters is highly dependent on the spark energy, which is generated through current density and is also the function of electrodes (tool and workpiece) materials' properties and EDM variables [22, 23]. The elliptical-shaped plasma channel generated by the tool electrode interacts with the workpiece electrode causing the material to melt producing circular craters.

The plasma channel is divided into two parts: one affects the tool electrode causing the wear phenomenon of the tool itself, and the second half affects the material surface. The

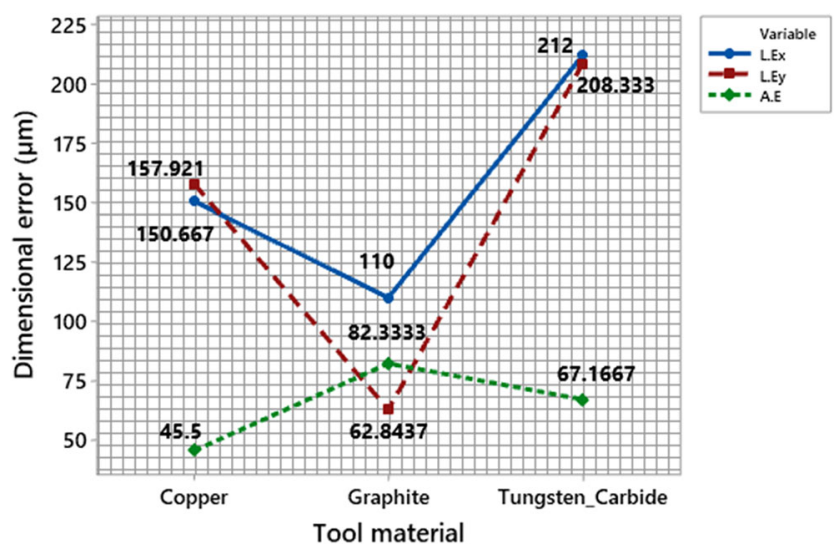

Fig. 10 Dimensional error produced through discharge machining process using copper, graphite, and tungsten carbide tool buildup and overlapping craters at the surface of both electrodes scaled up make a processed feature, for example, required shape of die and mold specifically micro-impressions. The oversized craters expanded away from the required area produce an error in geometry which is termed as the linear dimension error. The intensive energy integrated with the plasma pool permits an increase in the volume of the crater. The larger crater extent ultimately promotes the incidence of dimensional error [29]. Figure 11 exemplifies the influences of EDM process factors and electrode materials on the surface texture produced of micro-impression for controlled machining goal. However, axial dimension error (A.E) was experienced during EDM of D2 steel as shown in Fig. 10. From the changed behavior shown in Fig. 10, it can be inferred that the influence of the tool materials on axial error follows a distinct tendency. The difference in these trend lines is primarily because of the electrode attributes (see Table 2) and the combined effect of key characteristics in conjunction with workpiece material.

Excessive divergence of electrothermal attributes evident in Table 2, correlated with both electrodes, significantly control electron and ion movement which affect plasma plume. The copper tool holds the bottom spot in Fig. 10, and the least axial error may be realized. The amount of mean error is found to be in the range of 45-85 $\mu \mathrm{m}$. Contrarily, the graphite electrode loses the race of highest axial error. Nevertheless, it is merit stating that the maximum value of axial dimension error is $>85 \mu \mathrm{m}$. Decisively, to achieve minimum axial dimension error (A.E), copper would be the preferred choice. The surface quality is primarily dependent on crater size and its shape. The shape could be characterized as the depth and diameter of the craters. However, the roughness attribute is the function of many overlapping craters. In addition to this, the geometry of these craters is dependent on process variables and varies with the changing properties of materials [23]. Therefore, with the change in the materials, the surface integrity would be different in micro-impressions. The crater characteristics are also affected by the melt debris redeposition or their effective evacuation largely affecting arcing action. The entrapped debris layer inside the interaction area affects lowering the spark intensity [22]. Therefore, to effectively flush out this layer, $\mathrm{F}_{\mathrm{T}}$ plays a very important role. 
Fig. 11 The surface texture produced using copper, graphite, and tungsten carbide tool for micro-impression against controlled machining goal

\section{Copper electrode}
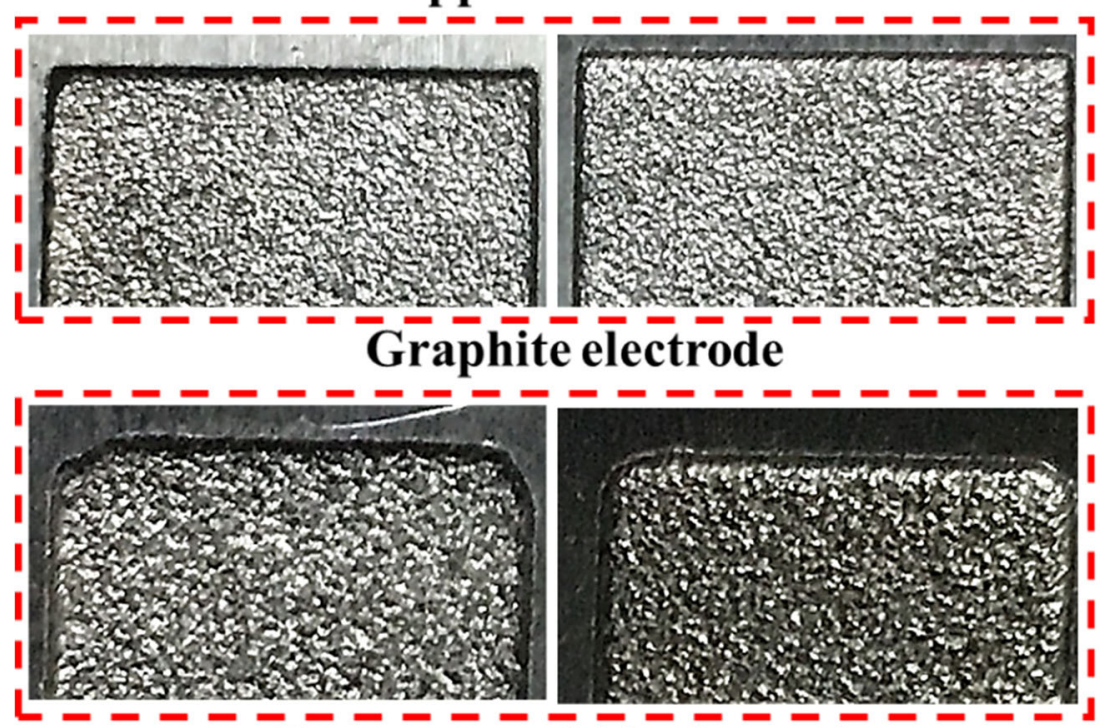

Tungsten carbide electrode

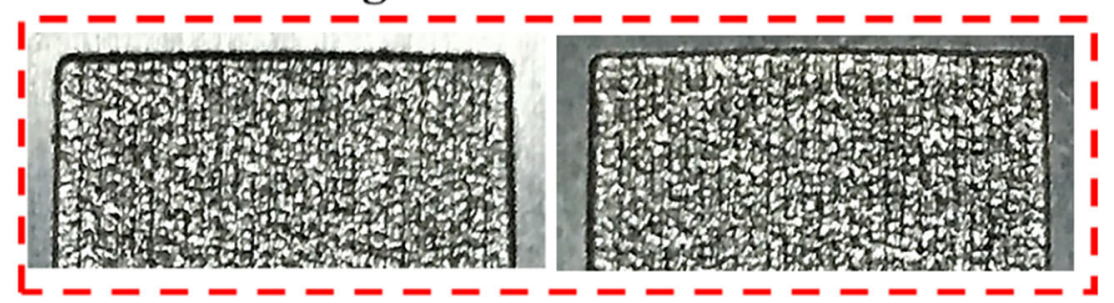

After successful completion and measuring dimensional attributes of micro-impression machined against 3 electrodes, the surface is analyzed through the microscope. The texture and geometries of craters support in augmenting the insight of the process. The micrographs pertaining to surface texture are accessible in Fig. 12 and Fig. 7-9. Each figure (Fig. 7-9) comprises three micro-graphical images, which include two of the positions at the workpiece surface at different magnifications (D2 steel), and one micrograph belongs to the tool. From thorough investigation based on the microscopic data, the microstructures of processed surfaces are shown which illustrates nominal surface texture and processes the effects against a particular electrode. The surface textures are comprised of multiple craters which are of circular geometry from the top view perspective. The melt pool is evacuated from the surface leaving the circular-shaped crater [15]. The 3D view of the crater is represented analogously to the bowl. The overlapping texture of the craters because of collapsed plasma makes the process stochastic. This behavior generates randomness in the geometry of the craters [15]. The properties of electrodes further enhance this effect making textures of the following types: (a) large and shallow, (b) small and shallow, (c) large and deep, and (d) small and deep [22]. These types of textures and the repetitive nature of plasma make a stacking structure resulting spongy network resulting in rough surface quality [23]. Since crater size determines the surface features, this does not represent as large to be good and small to be bad. The shallow and deep craters in accordance with random solidification of debris mainly contribute to surface features. The microstructure featuring crater texture and size is illustrated (see Fig. 12) after machining through tungsten carbide electrode, graphite electrode, and $\mathrm{Cu}$ tool electrode.

The copper electrode (see Fig. 12) produces a smoother surface of the spongy structure. The process variables also influence the surface characteristics along with the melting point of the electrodes. The erosive process takes place at both tool and workpiece. However, the electrode which is eroded more in the process will generate the targeted surface more irregular. The rough surface which is generated by graphite electrode due to inadequate heat conduction within the material is displayed in Fig. 12. As the sparking takes place ununiformly therefore, an irregular texture is realized at the machined surface. The physical phenomenon which promotes the erosion of the electrode is the medium density $(8.905$ $\left.\mathrm{g} / \mathrm{cm}^{3}\right)$ in conjunction with a low melting temperature (1083 ${ }^{\circ} \mathrm{C}$ ) of the $\mathrm{Cu}$ electrode. For graphite, the low density of the electrode $\left(1.77 \mathrm{~g} / \mathrm{cm}^{3}\right)$ is rendered as loose bonding of the atoms. As a result, low density together with comparatively highest melting temperature $\left(3300{ }^{\circ} \mathrm{C}\right)$ proclaimed the erosion 
Fig. 12 Microstructure and surface texture produced using copper, graphite, and tungsten carbide tool at different magnifications
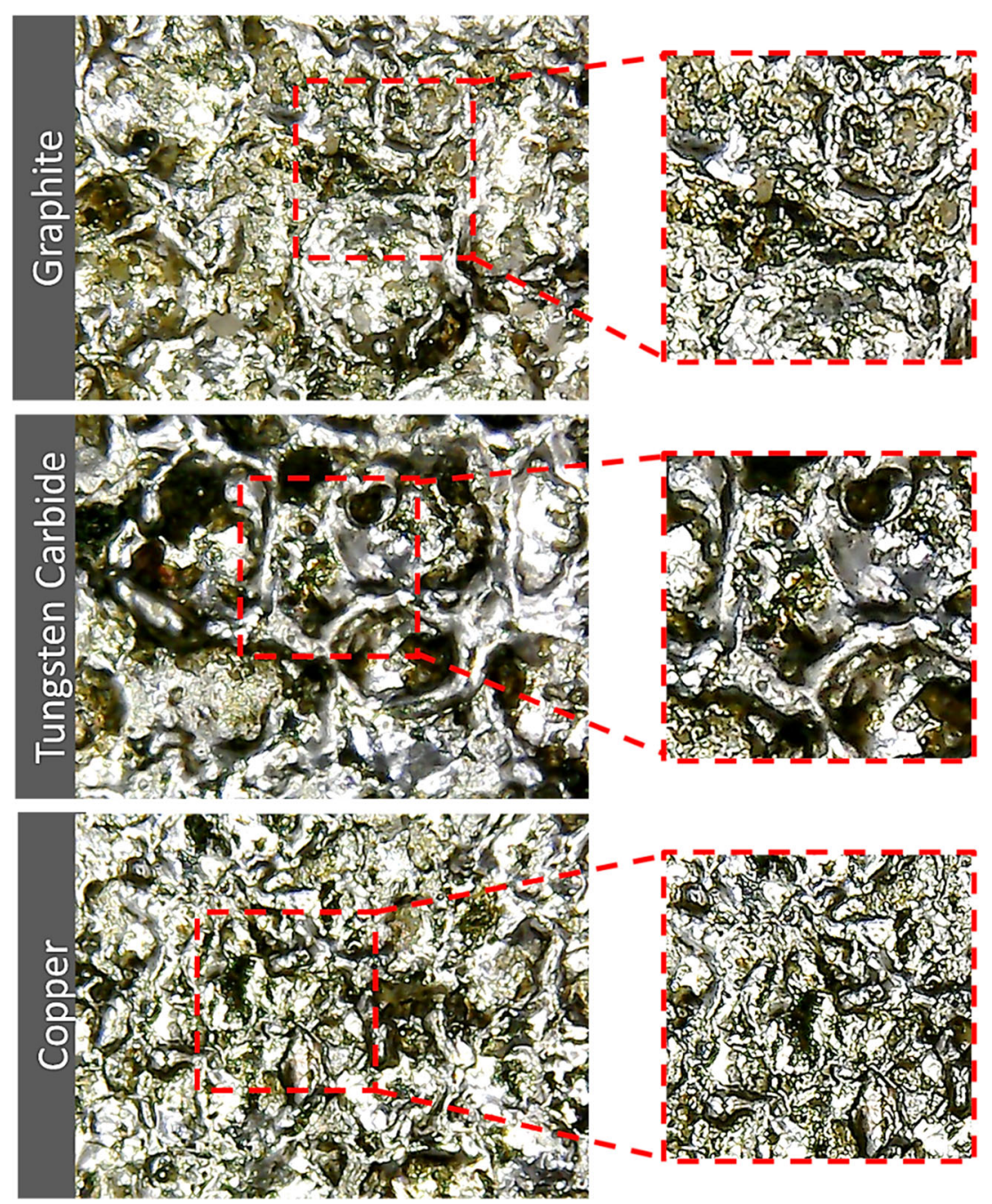

from the workpiece surface that ultimately produces poor surface finish at the targeted area. The texture of the workpiece surface is observed to be different with clear peripheries of craters (Fig. 12). This has led to creating course surfaces having larger and shallow craters [44].

Figure 12 demonstrates the micrographs related to the workpiece when tungsten carbide is employed as a tool electrode. The worst surface texture consisting of deep craters can be observed. The surface texture results from a significantly large heat energy pool are because of the low thermal conductivity of the tungsten carbide electrode $\left(88 \mathrm{~W}-\mathrm{m}^{-1} \mathrm{~K}^{-1}\right)$ as compared to the graphite tool $\left(400 \mathrm{~W}-\mathrm{m}^{-1} \mathrm{~K}^{-1}\right)$. Low thermal conductivity is associated with a high probability of tool wear [45]. The surface generated at the tool is analogous to the workpiece machined surface (replicated surface) $[22,46]$. The intense localized heating produced deep craters at the target surface as shown in Fig. 12. The tungsten carbide electrode produced the roughest features on the processed micro-impression's surface in comparison with graphite and $\mathrm{Cu}$ tool electrodes.
The rough surface texture is principally assigned with the thermophysical properties such as melting temperature of electrode, which is graphite $\left(3300{ }^{\circ} \mathrm{C}\right)$ in this case (see Fig. 13(a)). The intensive heating in the tool-workpiece interaction area melts the surface and vaporizes it. The unwanted material is flushed away from the targeted surface [15]. The impacts of intense heating are obvious in the case of the low melting temperature of the material $\left(1083{ }^{\circ} \mathrm{C}\right.$ : copper and $2727^{\circ} \mathrm{C}$ : tungsten carbide) as shown in Fig 13(b) and Fig 13(c). Another key characteristic from Table 2 is the density which shows the bond strength. The material which inherits low compactness will be more prone to wear during the discharge process, producing mediocre surface quality. If the melting temperature of the tool electrode is of high magnitude, the plasma pool is transferred to the workpiece resulting in more melting of its surface and acts opposite if the tool electrode has a lower melting temperature $[47,48]$. In the selected situation, the melting temperature of the graphite electrode $\left(3300{ }^{\circ} \mathrm{C}\right)$ is nearly double that of the $\mathrm{D} 2$ steel $\left(1421^{\circ} \mathrm{C}\right)$. The same goes for the tungsten carbide $\left(2727^{\circ} \mathrm{C}\right)$. Therefore, the deeper and 


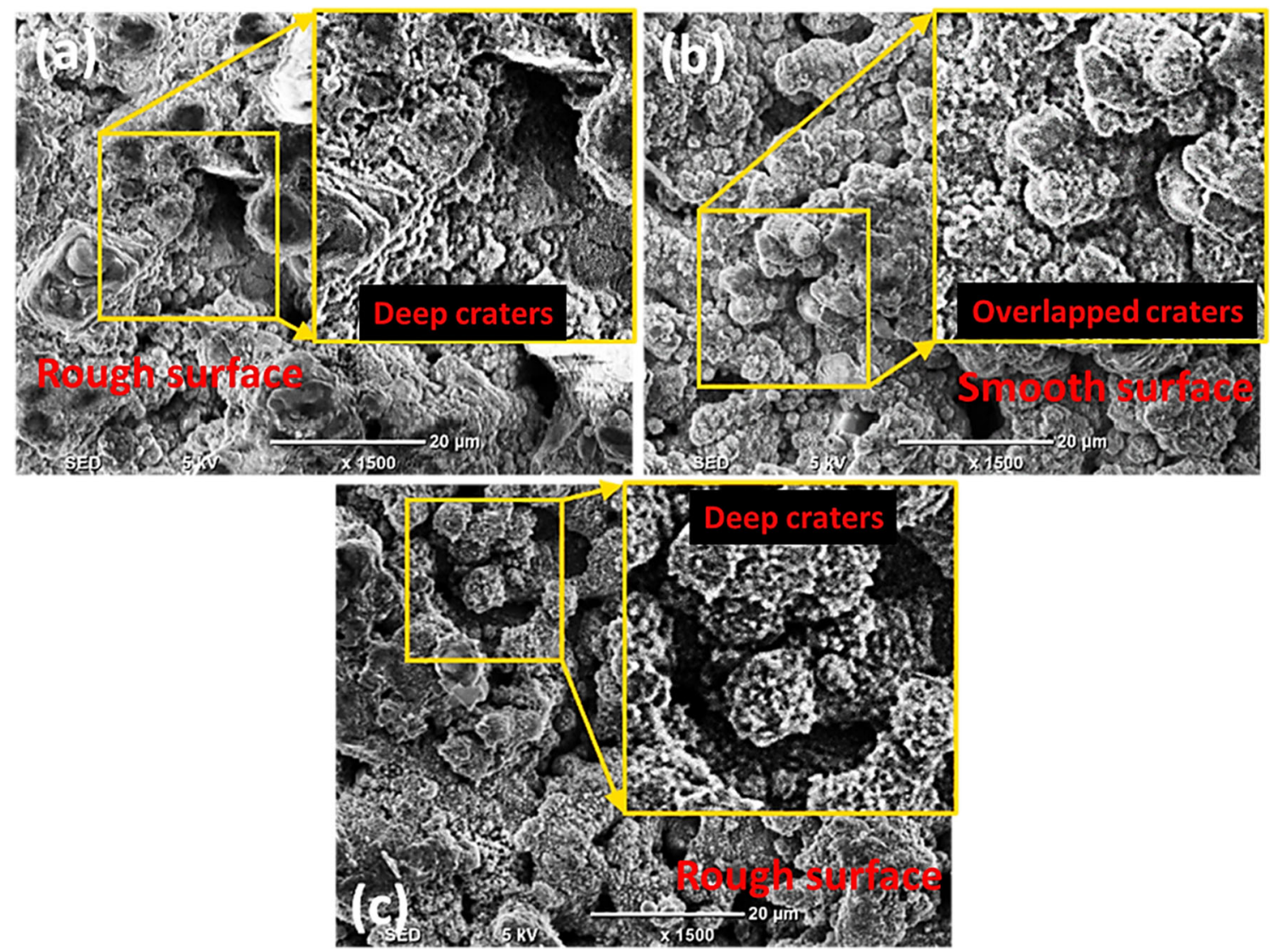

Fig. 13 SEM micrographs of the machined cavity with a graphite electrode, $\mathbf{b}$ copper electrode, and $\mathbf{c}$ tungsten carbide electrode

wider crater texture will be resulted on the workpiece surface compromising the surface integrity. However, as per the surface texture analyses of the processed surface through the $\mathrm{Cu}$ tool, the workpiece surface is comprised of prominently smooth texture, as displayed in Fig. 9.

\subsection{Parametric optimization and confirmatory experimentation}

Based on the findings realized in the previous section, it becomes obvious that the responses are conflicting in nature, i.e., reduction in the error along one particular direction may provoke the error in another cutting orientation. However, it is necessitated that errors which are representing cutting imperfections should remain minimal for all three cutting orientations. This aspect has not been specifically targeted so far during the repair applications using EDM as a cutting process. This issue has been addressed herein employing a multiresponse optimization methodology, namely the desirability approach $[22,49]$. The results of the desirability approach are presented in Fig. 14. According to this approach, the composite desirability is computed for all the experimental runs using the standard desirability functions' equations. The experimental setting for which the composite desirability value is maximum is considered as the optimum combination. In the present case, the optimal settings obtained via said analysis are shown in Table 4. The optimal parametric combination has also been validated through confirmatory trials. Three trials were conducted in this regard, and the results of which are tabulated in Table 4. It has been revealed from the results that the proposed setting holds a good degree of prediction accuracy, as the difference between actual and predicted error values is less than $2 \%$ for all three types of cutting errors.

\section{Conclusions}

The potentiality of three different classes of electrodes, i.e., metal $(\mathrm{Cu})$, a nonmetal (graphite), and ceramics (tungsten carbide), has been comprehensively explored in this research in the context of repair applications. In the said applications (specifically die and molds), the use of EDM is common. However, it is challenging to control the dimensional accuracy in the different dimensions of an already machined cavity/ profile during the repair because of the stochastic nature of EDM. But it is an essential requirement that warrants the effective usage of the die and mold. Therefore, the selection of the electrode material along with the appropriate levels of other EDM parameters is crucial to confirm the accurate formation of the cavity. This aspect has not been thoroughly 
Table 4 Measured responses at optimum parametric settings

\begin{tabular}{|c|c|c|c|c|c|c|c|c|c|c|}
\hline \multirow{2}{*}{$\begin{array}{l}\text { Sr. } \\
\text { No. }\end{array}$} & \multicolumn{7}{|c|}{ Process parameters } & \multicolumn{3}{|c|}{ Response indicators } \\
\hline & $\begin{array}{l}\mathrm{S}_{\mathrm{T}} \\
(\mu \mathrm{s})\end{array}$ & $\mathrm{T}_{\mathrm{M}}$ & $\begin{array}{l}\mathrm{P}_{\mathrm{ON}} \\
(\mu \mathrm{s})\end{array}$ & $\begin{array}{l}P_{\mathrm{OFF}} \\
(\mu \mathrm{s})\end{array}$ & $\begin{array}{l}\mathrm{F}_{\mathrm{T}} \\
(\mu \mathrm{s})\end{array}$ & $\begin{array}{l}\mathrm{I}_{\mathrm{P}} \\
(\mathrm{A})\end{array}$ & $\begin{array}{l}V_{S} \\
(V)\end{array}$ & $\begin{array}{l}\text { L.E } E_{X} \\
(\mu \mathrm{m})\end{array}$ & $\begin{array}{l}\text { L.E. } E_{Y} \\
(\mu \mathrm{m})\end{array}$ & $\begin{array}{l}\text { A.E } \\
(\mu \mathrm{m})\end{array}$ \\
\hline 1 & 9 & 1 & 70 & 90 & 3 & 8 & 5 & 103.10 & 79.02 & 15.09 \\
\hline 2 & 9 & 1 & 70 & 90 & 3 & 8 & 5 & 98.91 & 78.87 & 18.10 \\
\hline \multirow[t]{4}{*}{3} & 9 & 1 & 70 & 90 & 3 & 8 & 5 & 101.99 & 78.52 & 17.01 \\
\hline & & & & & \multicolumn{3}{|c|}{ Avg. experimental value } & 101.33 & 78.80 & 16.73 \\
\hline & & & & & \multicolumn{3}{|c|}{ Predicted value } & 100.06 & 77.26 & 16.95 \\
\hline & & & & & \multicolumn{3}{|c|}{ Error \% } & 1.25 & 1.95 & 1.31 \\
\hline
\end{tabular}

discussed in the past with regard to the geometrical errors (L.E $E_{X}$, L.E $E_{Y}$, and A.E ). Therefore, this research dedicatedly focuses on the reduction of the geometric errors considering three electrodes and six EDM parameters as input variables. Taguchi's L18 design was used for performing the experiments. The results are then rigorously investigated using statistical tests. The optical micrographs are also included herein to explain the process science under different cutting conditions. Considering the findings of the detailed analyses and their discussion, the following conclusions are drawn:

1. The magnitude of overcutting in lateral dimensions (L. $E_{X}$ and L.E $E_{Y}$ ) is notably high in the contest to that found in axial cutting orientation (A.E). The maximum mean values of $\mathrm{L} . \mathrm{E}_{\mathrm{X}}$ and $\mathrm{L} . \mathrm{E}_{\mathrm{Y}}$ recorded during experimentation are $212 \mu \mathrm{m}$ and $208 \mu \mathrm{m}$, respectively, which are approximately 2.5 times of the maximum mean value of A.E, i.e., $82 \mu \mathrm{m}$.
2. For lateral dimensional errors (L. $E_{X}$ and L.E $E_{Y}$ ), the electrode of graphite has proved to be a promising choice in comparison to the other two types. In the case of L. $E_{X}$, the mean error value realized with graphite electrode is $37 \%$ lesser in magnitude as compared to that obtained with $\mathrm{Cu}$ electrode. This percentage further upsurges when the comparison is made with the tungsten carbide electrode, reaching a maximum of $92.7 \%$. When $L . E_{Y}$ is considered, the graphite electrode provides 1.5 times and 2.3 times lesser mean geometric errors in comparison to that achieved with copper and tungsten carbide.

3. The maximum lateral dimensional errors, i.e., L. $E_{X}$ and L. $E_{Y}$, are found in the case when the tungsten carbide electrode is engaged. As the tungsten carbide is not a good conductor of heat $(88 \mathrm{~W} / \mathrm{m} \mathrm{K})$, it promotes the highest error.

4. The electrode of copper is noticed to be the most appealing option for reducing the A.E. The mean A.E obtained
Fig. 14 Multi-response optimization for microimpression against controlled machining goal

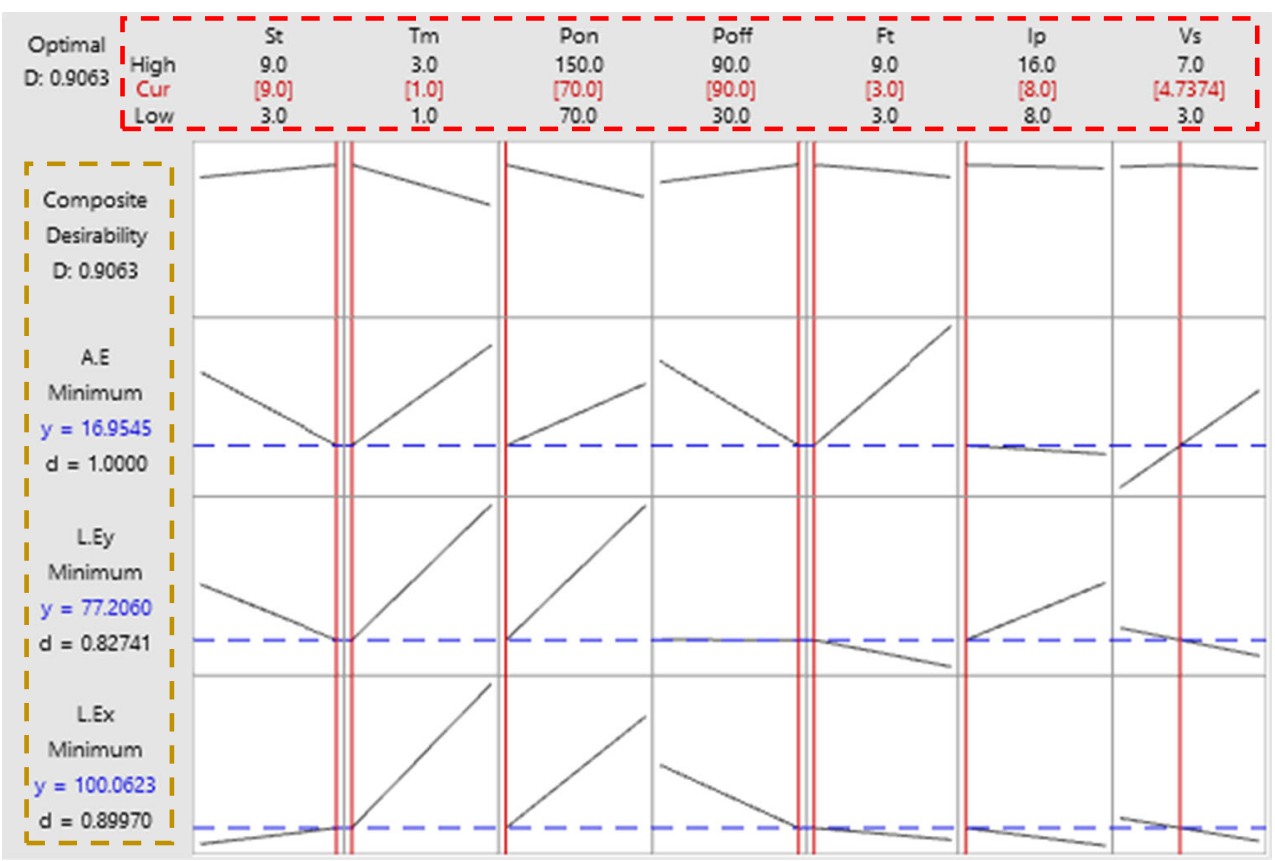


with $\mathrm{Cu}$ electrode is $80.9 \%$ and $47.6 \%$ lower than that achieved in case graphite and tungsten carbide, respectively.

5. The copper electrode produces a smoother surface of the spongy structure. For graphite, the low density of the electrode $\left(1.77 \mathrm{~g} / \mathrm{cm}^{3}\right)$ is rendered as loose bonding of the atoms.

6. The optimum combination that ensures the minimal values of all the geometric errors L.E $E_{X}, L . E_{Y}$ and A.E $(\mu \mathrm{m})$ are established, i.e., $\mathrm{S}_{\mathrm{T}}=9 \mu \mathrm{s}, \mathrm{T}_{\mathrm{M}}=\mathrm{Cu}, \mathrm{P}_{\mathrm{ON}}=70$ $\mu \mathrm{s}, \mathrm{P}_{\mathrm{OFF}}=90 \mu \mathrm{s}, \mathrm{F}_{\mathrm{T}}=3 \mu \mathrm{s}, \mathrm{I}_{\mathrm{P}}=8 \mathrm{~A}$, and $\mathrm{V}_{\mathrm{S}} 5 \mathrm{~V}$, and shows a good agreement between predicted and experimental values.

The A.E shows the axial error which sheds light on achieving desired depth. However, to evaluate the functionality of electrodes in terms of undercut and overcut, lateral dimensional errors are investigated. The motivation behind these response parameters is for die repair applications where it is not always necessary to machine thorough holes. The possible extension of current research could be the comparison of errors produced at the entry of profiles and the exit of profiles.

\section{Declarations}

Ethics approval This article does not contain any studies with human participants performed by any of the authors.

Conflict of Interest The authors declare that they have no competing interests.

Open Access This article is licensed under a Creative Commons Attribution 4.0 International License, which permits use, sharing, adaptation, distribution and reproduction in any medium or format, as long as you give appropriate credit to the original author(s) and the source, provide a link to the Creative Commons licence, and indicate if changes were made. The images or other third party material in this article are included in the article's Creative Commons licence, unless indicated otherwise in a credit line to the material. If material is not included in the article's Creative Commons licence and your intended use is not permitted by statutory regulation or exceeds the permitted use, you will need to obtain permission directly from the copyright holder. To view a copy of this licence, visit http://creativecommons.org/licenses/by/4.0/.

\section{References}

1. ul HMA, Hussain S, Ali MA et al (2021) Evaluating the effects of nano-fluids based MQL milling of IN718 associated to sustainable productions. J Clean Prod 310:127463. https://doi.org/10.1016/j. jclepro.2021.127463

2. Farooq MU, Hussain A, Masood T, Habib MS (2021) Supply chain operations management in pandemics: a state-of-the-Art review inspired by COVID-19. Sustainability 13:2504

3. Altan T (1987) Design and manufacture of dies and molds. CIRP Ann 36:455-462. https://doi.org/10.1016/S0007-8506(07)60747-1
4. De Lacalle LL, Lamikiz A, Muñoa J et al (2006) Improving the high-speed finishing of forming tools for advanced high-strength steels (AHSS). Int J Adv Manuf Technol 29:49-63

5. Jhavar S, Paul CP, Jain NK (2013) Causes of failure and repairing options for dies and molds: a review. Eng Fail Anal 34:519-535

6. Lacalle LNLD, Lamikiz A, Salgado MA et al (2002) Process planning for reliable high-speed machining of moulds. Int J Prod Res 40:2789-2809. https://doi.org/10.1080/00207540210140068

7. Yakoubi K, Montassir S, Moustabchir H, Elkhalfi A, Pruncu CI, Arbaoui J, Farooq MU (2021) An extended finite element method (XFEM) study on the elastic T-stress evaluations for a notch in a pipe steel exposed to internal pressure. Mathematics 9:507. https:// doi.org/10.3390/math9050507

8. Rodríguez A, de Lacalle LL, Celaya A et al (2012) Surface improvement of shafts by the deep ball-burnishing technique. Surf Coat Technol 206:2817-2824

9. de Lacalle LNL, Lamikiz A, Sánchez JA, Arana J-L (2002) Improving the surface finish in high speed milling of stamping dies. J Mater Process Technol 123:292-302

10. de Lacalle LL, Lamikiz A, Sánchez JA, Salgado MA (2004) Effects of tool deflection in the high-speed milling of inclined surfaces. Int J Adv Manuf Technol 24:621-631

11. Lamikiz A, De Lacalle LL, Sánchez JA, Salgado MA (2005) Cutting force integration at the CAM stage in the high-speed milling of complex surfaces. Int J Comput Integr Manuf 18:586-600

12. Travieso-Rodríguez JA, Dessein G, González-Rojas HA (2011) Improving the surface finish of concave and convex surfaces using a ball burnishing process. Mater Manuf Process 26:1494-1502

13. López de Lacalle LN, Rodriguez A, Lamikiz A et al (2011) Fiveaxis machining and burnishing of complex parts for the improvement of surface roughness. Mater Manuf Process 26:997-1003

14. Khan SA, Rehman M, Farooq MU, Ali MA, Naveed R, Pruncu CI, Ahmad W (2021) A detailed machinability assessment of DC53 steel for Die and mold industry through wire electric discharge machining. Metals 11:816. https://doi.org/10.3390/met11050816

15. Farooq MU, Ali MA, He Y, et al (2020) Curved profiles machining of Ti6Al4V alloy through WEDM: Investigations on geometrical errors. J Mater Res Technol 9(6):16186-16201

16. Hanif M, Ahmad W, Hussain S, Jahanzaib M, Shah AH (2019) Investigating the effects of electric discharge machining parameters on material removal rate and surface roughness on AISI D2 steel using RSM-GRA integrated approach. Int J Adv Manuf Technol 101:1255-1265

17. Jadidi A, Azhiri RB, Teimouri R (2020) Electrical Discharge turning by assistance of external magnetic field, part I: study of MRR and dimensional accuracy. Int J Lightweight Mater Manuf 3(3): 265-276

18. Liu K, Lauwers B, Reynaerts D (2010) Process capabilities of micro-EDM and its applications. Int J Adv Manuf Technol 47: $11-19$

19. Tzeng Y (2008) Development of a flexible high-speed EDM technology with geometrical transform optimization. J Mater Process Technol 203:355-364

20. Bhaumik M, Maity K (2018) Effect of different tool materials during EDM performance of titanium grade 6 alloy. Engineering Science and Technology, an International Journal 21:507-516. https://doi.org/10.1016/j.jestch.2018.04.018

21. Tricarico C, Delpretti R, Dauw DF (1988) Geometrical simulation of the EDM die-sinking process. CIRP Ann 37:191-196

22. Umar Farooq M, Pervez Mughal M, Ahmed N, Ahmad Mufti N, alAhmari AM, He Y (2020) On the investigation of surface integrity of Ti6Al4V ELI using Si-mixed electric discharge machining. Materials 13(7):1549. https://doi.org/10.3390/ma13071549

23. Mughal MP, Farooq MU, Mumtaz J, Mia M, Shareef M, Javed M, Jamil M, Pruncu CI (2021) Surface modification for osseointegration of Ti6Al4V ELI using powder mixed sinking 
EDM. J Mech Behav Biomed Mater 113:104145. https://doi.org/ 10.1016/j.jmbbm.2020.104145

24. Dimla DE, Hopkinson N, Rothe H (2004) Investigation of complex rapid EDM electrodes for rapid tooling applications. Int J Adv Manuf Technol 23:249-255

25. Bhaumik M, Maity K (2019) Effect of electrode materials on different EDM aspects of titanium alloy. Silicon 11:187-196

26. Zhang Y, Wang C, Wang Y, Ni Q, Ji L (2019) Geometric accuracy improvement by using electrochemical reaming with a helical tube electrode as post-processing for EDM. Materials 12:3564

27. Nguyen PH, Banh TL, Mashood KA, Tran DQ, Dong Pham V, Muthuramalingam T, Duc Nguyen V, Nguyen DT (2020) Application of TGRA-based optimisation for machinability of high-chromium tool steel in the EDM process. Arab J Sci Eng 45: $5555-5562$

28. Phan NH, Van Dong P, Dung HT et al (2021) Multi-object optimization of EDM by Taguchi-DEAR method using AlCrNi coated electrode. Int J Adv Manuf Technol 116:1429-1435. https://doi. org/10.1007/s00170-021-07032-3

29. Ishfaq K, Farooq MU, Anwar S, Ali MA, Ahmad S, M. elSherbeeny A (2021) A comprehensive investigation of geometrical accuracy errors during WEDM of A16061-7.5\% SiC composite. Mater Manuf Process 36(2):362-372. https://doi.org/10.1080/ 10426914.2020.1832683

30. Sahu DR, Mandal A (2020) Critical analysis of surface integrity parameters and dimensional accuracy in powder-mixed EDM. Mater Manuf Process 35:430-441

31. Ahmad Mufti N, Rafaqat M, Ahmed N, Qaiser Saleem M, Hussain A, al-Ahamri AM (2020) Improving the performance of EDM through relief-angled tool designs. Appl Sci 10:2432

32. Ahmad S, Chendang RN, Supawi A et al (2019) Material removal rate and machining accuracy of electrical discharge machining (EDM) of Inconel 718 using copper electrode. In: IOP Conference Series: Materials Science and Engineering. IOP Publishing, p 012006

33. Azhiri RB, Bideskan AS, Javidpour F, Tekiyeh RM (2019) Study on material removal rate, surface quality, and residual stress of AISI D2 tool steel in electrical discharge machining in presence of ultrasonic vibration effect. Int J Adv Manuf Technol 101:2849-2860

34. Dewangan S, Gangopadhyay S, Biswas CK (2015) Study of surface integrity and dimensional accuracy in EDM using Fuzzy TOPSIS and sensitivity analysis. Measurement 63:364-376

35. Nguyen MD, Rahman M, San Wong Y (2012) Enhanced surface integrity and dimensional accuracy by simultaneous micro-ED/EC milling. CIRP Ann 61:191-194

36. Sanchez JA, de Lacalle LL, Lamikiz A, Bravo U (2002) Dimensional accuracy optimisation of multi-stage planetary EDM. Int J Mach Tools Manuf 42:1643-1648

37. AZOM Materials (2020) Material Direectory | Materials Engineering. In: AZOM.com. https://www.azom.com/. Accessed 26 Jun 2020

38. Ahmed N, Anwar S, Ishfaq K et al (2019) The potentiality of sinking EDM for micro-impressions on Ti-6Al-4V: keeping the geometrical errors (axial and radial) and other machining measures (tool erosion and work roughness) at minimum. Sci Rep 9:1-18
39. Ali MA, Ishfaq K, Raza MH, Farooq MU, Mufti NA, Pruncu CI (2020) Mechanical characterization of aged AA2026-AA2026 overcast joints fabricated by squeeze casting. Int J Adv Manuf Technol 107:3277-3297. https://doi.org/10.1007/s00170-02005242-9

40. Long BT, Phan NH, Cuong N, Jatti VS (2016) Optimization of PMEDM process parameter for maximizing material removal rate by Taguchi's method. Int J Adv Manuf Technol 87:1929-1939

41. Jawad M, Jahanzaib M, Ali MA, Farooq MU, Mufti NA, Pruncu CI, Hussain S, Wasim A (2021) Revealing the microstructure and mechanical attributes of pre-heated conditions for gas tungsten arc welded AISI 1045 steel joints. Int J Press Vessel Pip 192:104440. https://doi.org/10.1016/j.ijpvp.2021.104440

42. Ishfaq K, Anwar S, Ali MA, Raza MH, Farooq MU, Ahmad S, Pruncu CI, Saleh M, Salah B (2020) Optimization of WEDM for precise machining of novel developed Al6061-7.5\% SiC squeezecasted composite. Int J Adv Manuf Technol 111:2031-2049. https://doi.org/10.1007/s00170-020-06218-5

43. Narasimhan J, Yu Z, Rajurkar KP (2005) Tool wear compensation and path generation in micro and macro EDM. J Manuf Process 7: 75-82

44. Dewangan S, Gangopadhyay S, Biswas CK (2015) Multi-response optimization of surface integrity characteristics of EDM process using grey-fuzzy logic-based hybrid approach. Engineering Science and Technology, an International Journal 18:361-368. https://doi.org/10.1016/j.jestch.2015.01.009

45. Mohanty CP, Mahapatra SS, Singh MR (2017) An intelligent approach to optimize the EDM process parameters using utility concept and QPSO algorithm. Engineering Science and Technology, an International Journal 20:552-562. https://doi.org/10.1016/j. jestch.2016.07.003

46. Bobbili R, Madhu V, Gogia AK (2015) Modelling and analysis of material removal rate and surface roughness in wire-cut EDM of armour materials. Engineering Science and Technology, an International Journal 18:664-668. https://doi.org/10.1016/j.jestch. 2015.03.014

47. Al-Khazraji A, Amin SA, Ali SM (2016) The effect of SiC powder mixing electrical discharge machining on white layer thickness, heat flux and fatigue life of AISI D2 die steel. Engineering Science and Technology, an International Journal 19:1400-1415. https://doi.org/10.1016/j.jestch.2016.01.014

48. Phate MR, Toney SB (2019) Modeling and prediction of WEDM performance parameters for $\mathrm{Al} / \mathrm{SiCp} \mathrm{MMC}$ using dimensional analysis and artificial neural network. Engineering Science and Technology, an International Journal 22:468-476. https://doi.org/ 10.1016/j.jestch.2018.12.002

49. Sivaprakasam P, Hariharan P, Gowri S (2014) Modeling and analysis of micro-WEDM process of titanium alloy (Ti-6Al-4V) using response surface approach. Engineering Science and Technology, an International Journal 17:227-235. https://doi.org/10.1016/j. jestch.2014.06.004

Publisher's note Springer Nature remains neutral with regard to jurisdictional claims in published maps and institutional affiliations. 